\title{
An Evolutionary Approach-Based Methodology for Egyptian Utility Restoration
}

\author{
إستعادة الثُشبكة الكهربية المصرية لوضع ها قبل الخطا باستخدام \\ منهجية الطنق التطويزية
}

M. M. El-Saadawi

A. E. Hassan

R. R. Ebrahim

Depr. of Electrical Engineoring, Faculty of Engineering,

Munsoura Universioy

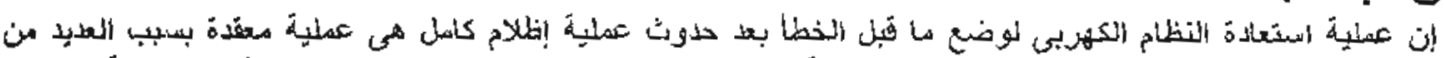

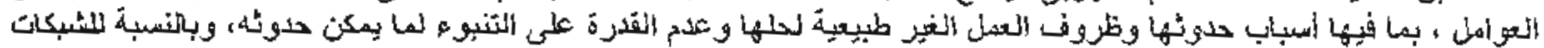

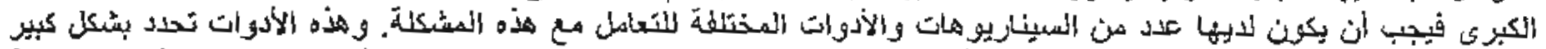

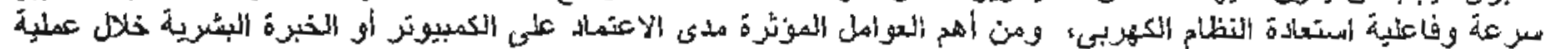

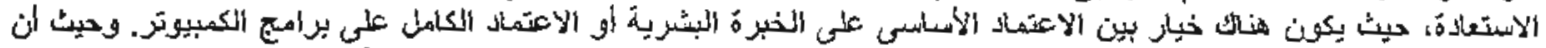

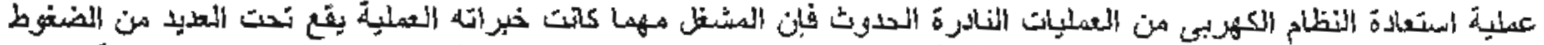

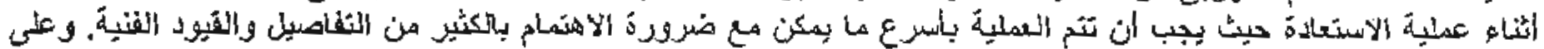

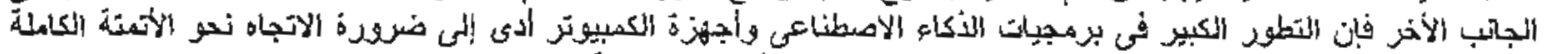

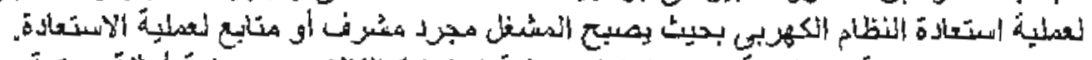

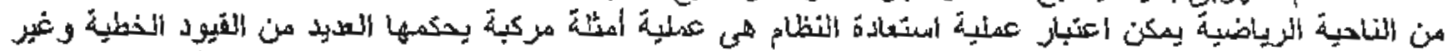

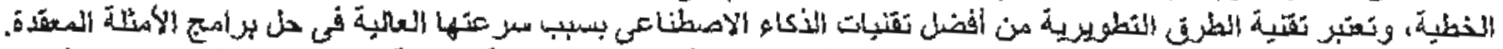

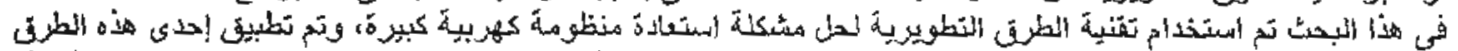

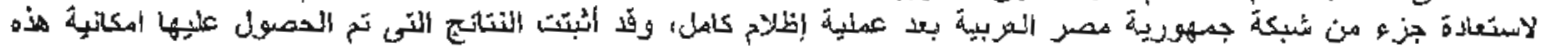

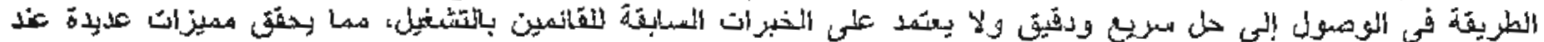

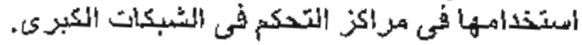

\section{Abstract}

Restoration of a large efectric grid alter a partial or complete system blackout is a difficult task complicated by many factors, including unknown ause, abuormal operating conditions, infrequently used procedures and unpredictable system contigurations. Large utilities must have different scenarios and tools to deat with this problem. The coordination and overall organization of the several aspects of the restoration process will largely determine the effectiveness of the restoration and its speed of progress. The most basic determinants of this organization are the relative roles played by the operator and the computer. Thus there arises a choice betweon two basic arganizing principles: operator dominated principle or computer dominated principle. In actual power system operation, severe restoration situations oceur infreguently. Therefore, when they do vecur, operators have had litlle first-hand, on-thejob experience. Even so, they are under pressure to restore the system as quickly as possitole, while paying close attention to many technical details. On other hand the grent progress in both artificial intelligence soltware and computer hardware, incenses the tendency to fully auloninted the restoration problem, so that the operator plays the role of an observer or supervisor.

In mathematical terms, the restoration problem inay be described as a multi-objective, nulti-stage, comblatorial, nonlinear, constralned optimization problem. Evolutionary Approach (EA) technique is one of the most promising artificial intelligence techniques because it is proven 10 be bofh very fast and effective when applied to a diverse set of optimization problems.

In this paper a proposed Evolutionary Approach-based methodology is used to solve the restoration problem of a large electric system with muttiple generation units and transmission foops. The methodology is applied to restore a sector of Egyptinn Ulility after a complete blackout. The obtained results show effectiveness and validity of the proposed methodology compared to pure human experience in Egyptian National Energy Control Center.

Keywords:

Power System Restoration; Evolutionary Approaches; Power Flow; Egyotian Uility 


\section{Introduction}

Power system blackouts are rare events $[1,2]$. However, when they occur, the effects on commerce, industry and everyday life of the general population can be quit severe. In the aflermath of a blackout, a subject of critical importance is the rapidity with which electric service is restored [3]. Blackouts are caused by a variety of phenomena. The causes include weaknesses in the infrastructure, storms, the general climate and human error. The consequences can be far ranging: disruption to industry, transport problems and a variety of social and political effects [2].

Restoration of a large and interconnected grid from a complete shutdown is a highly complex operation involving many technical and non-technical constraints. Most operating companies are maintaining restoration procedures based on certain operating philosophies, practices, and familiarity with power plant restart and power system operation.

The coordination and overall crganization of the several aspects of the rustoration process will largely determine the effectiveness of the restoration and its speed of progress. The most basic determinants of this organization are the relative roles played by the operator and the computer. Increasing sophistication in analysis and computational programs, including those derived from arlificial intelligence, raises the computer to a significance somewhat comparable to that of the operator. Thus there arises a choice between two basic organizing principles: operator dominated principle or computer doninated principle.

In order to improve the system restoration when a system blackout occurs many utilities contain pre-established resturation procedures and guidelines to advise the system operator to restore the system. However, these restoration guidelines and procedures have not enabled the system operator to achieve successful restoration plans when unforeseen restoration scenarios are encountered. The main factor that explains this lack of success is that after the occurrence of a wide-area disturbance the system operator is under intense pressure to restore the system in the minimum time possible. The inability to deal with this pressure and the appearance of unexpected resioration scenarios not covered in the restoration guidelines are known to lead the system operators to unsuccessful restoration attempts and the prolongation of the system disturbance.

On the other hand, the great progress in both artificial intelligence software and computer hardware increases the tendency to fully automated the restoration problem.

At that situation practical and generic computer tools to support system dispatchers in their decision-making have been recently proposed. The restoration strategy should include optimization techniques to minimize available un-served loads subject to constraints during restoration, use of tie lines, and time to restoration [4].

In mathematical terms, power system restoration problem is a very complex combinational problem that can be formulated as a multi-stage, non-linear, continuous and binary constrained optimization problem. The main objective of the restoration process is to restore service to loads as quickly as possible keeping a feasible configuration.

Mary approaches have been applied to the power system restoration problem such as expert systems, mathematical programming and evolutionary strategy [5]. In fact, the application of these techniques to power system restoration problem, especially the mathematical programming approach, has been limited to a small number of publications. Actually most of these approaches are validated using radial power systems or distribution systems.

In $[3,6,7$ and 8$]$ authors presented expert system for power system restoration. But, the approach was formulated and tested in a radial test system. In $[9,10,11$, and 12$]$ authors presented mathematical programming approaches, but their 
approaches were limited to small and simple cases.

In $[7,13,14$, and 15], authors proposed evolutionary strategy approaches to deal with that problem. D. Kirschen [7] presented a multi-agent approach to power system restoration; the approacl was validated and tested on a radial power system. A.S. Bretas, et.al [15], presented an artificial neural network approach for power system restoration. The proposed approach is very complex and not reliable enough for real time restoration process.

The EA technique is one of the most promising artificial intelligence techniques because it is proven to be both very tast and effective when applied to a diverse set of optimization problems. The technique is based on a simple concept, and it can be easily implemented with computer codes. It has attracted many researchers' attention and has been applied with great success to fairly broad engineering problems [16].

In this paper a proposed EA-based methodology is used to solve the restoration problem of a large electric system with multiple generation units and transmission loops. The methodology is applied to restore a sector of Egyptian Utility after a complete blackoui.

\section{Evolutionary Approaches}

Evolutionary Approach (EA) is the collective name for a range of problemsolving techniques based on principles of biological evolution, such as natural selection and genetic inheritance. These techniques are being increasingly widely applied to a varjely of problems, ranging from practical applications in industry and commerce to leading-edge scientific research. The basic idea behind all these EA variants is commonly the same from a unifying viewpoint. On availability of a population of individuals, natural selection, which is based on the principle of survival of the fittest following the existence of environmental pressures, is exersised to choose individuals that could better fit the environment. The operations involved are as follows. Given a fitness function to be optimized, a set of candidate solutions is randomly generated. The candidate solutions are assessed by the fitness function that indicates an abstract of fitness measure. Based on the fitness values, fitter candidate solutions have a better chance to be selected to seed the next generation [17].

As explained in [18] one of the main advantages of EA is that it is conceptually simple and easy to use. An EA process normally covers random initialization of a population of candidate solutions, followed by some iterative variation and selection strategy, and by evaluation of candidate solutions in accordance with a performance index. This process is relatively simple, as compared with, for example, model-based approaches that deal with complicated mathematical formulation of the system under scrutiny. The applicability of EA is broad and comprehensive, covering most problems that can be cast as an optimization task. These Approaches seem to be particularly sujted for multi-objective, combinatorial, nonlinear, constrained optimization problem because they process a set of solutions in parallel, possibly exploiting similarities of solutions by recombination, Zitzler and Thiele, [19] suggest that multi objective search and optimization might be a problem area where EA's do better than other blind search strategies.

Evolutionary techniques mostly involve metabeuristic optimization algorithms such as:

- evolutionary algorithms (comprising genetic algorithms, evolutionary programming, evolution strategy and genetic programming)

- swarni intelligence (comprising particle swam optimization and ant colony optimization)

\section{Proposed Methodology}

To simplify the solution of restoration problem, a proposed EA-based methodology is suggested. In this paper the Particle Swam Optimization (PSO) teclunique is 
used in numerical application as an example of the EA technique. The proposed methodology is divided into three main components as shown by Figure 1.

i. Input Component: this component is a Inodule which deals with input data: network data, topology configuration, and data for EA technique.

ii. Solution Techniques Component: this component consists of three modules and it will be explained in details in the following section. The three modules are: sub topology list module, power flow module and particle swarm optimization module. iii. Output Component: this component gives the solution results of new topology configuration.

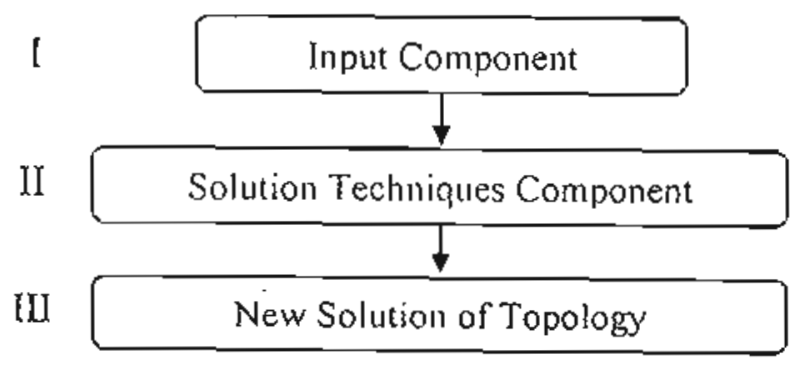

Figure I Main components of the proposed methodology

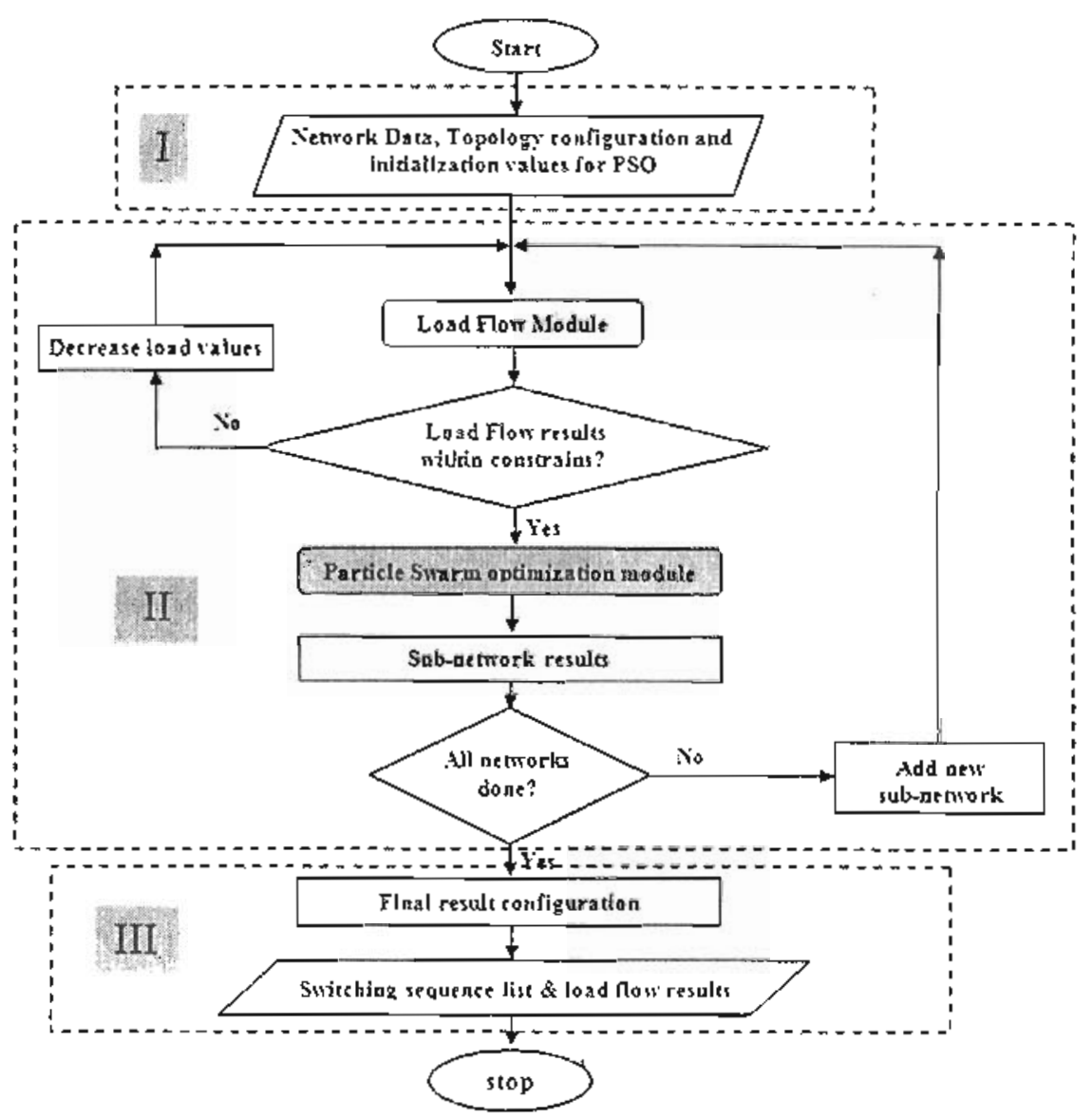

Figure 2 Flow chart of the proposed methodology

Figure 2 explains a flow chart of the proposed methodology. All components of the methodology interact to present the switching action sequence. And this could lead to restore the system after the blackout. In general, the approach is to sectionalize the power system into a number of subsystems and restore the whole blackout area step by step based on objective function and constraints of each sub area.

\subsection{Input Component}

In this section each element and all data included in the problem are defined and prepared. 


\section{- Network data}

The main elements of a power system are generator, buses, transformers, loads, and transmission lines and circuit breakers.

- Topology configuration

At this part the network is mapped as a graph and the connections between its components (elements and circuit breakers) are described and listed.

\section{- PSO initialization values}

PSO starts with a population of random solutions particles in a $\mathrm{D}$. dimension space. The particle position is represented by $x_{i}=\left(x_{i 1}, x_{i 2}, \ldots, x_{10}\right)$. Each particle keeps track of its coordinates in hyperspace, which are associated with the best solution it has achieved so far. The value of the fitness for particle $\mathrm{i}\left(\mathrm{p}_{\text {best }}\right)$ is also stored as $\mathrm{p}_{\mathrm{i}}=\left(\mathrm{p}_{\mathrm{il}}, \mathrm{p}_{\mathrm{i} 2}, \ldots, \mathrm{p}_{\mathrm{iD}}\right)$, it initially random values. The global version of the PSO keeps track of the overall best value (gest), and its location, also it obtains values of (gbest), for every particle in the population $[16,20]$.

\subsection{Solution Technique Components}

The solution technique of the problem is divided into three modules:

\section{i. Sub topology list module}

In this module the available restored paths are checked, the least path is choose after executing power flow and PSO techniques.

\section{ii. Power flow module}

Power Flow is used for steady state solution of an electric power utility. The power hlow analysis for a certain electric power system under a desired operating condition is a simulation of this system, through mathematical equations, that will provide the real and reactive power flow through the system voltage and angles of its buses. This information will determine if any equipment of the power system is operating under unacceptable conditions or violating any constraints.

\section{iii. PSO module}

This module solves the optimization problem to selected minimum path, and that algorithm can be illustrated by the following steps:

Stepl: For each particle, evaluate the desired optimization fitness function (objective function (minimum unserved load) in D variables .

Step2: Compare particle's fitness evaluation with its initial pbes. If current value is better than initial pbest, ther set pbest equal to the current value, and $\mathrm{Pi}$ equals to the current location $X i$ in Ddimensional space

Step3: Change the velocity and position of the particle according to Equations (1) and (2).

Step4: A stopping criteria of the algorithm is usuaily a sufficiently good fitness or a maximum number of iterations

\subsection{Output Component}

It shows the result clearly, easily and saves the best network topology configuration, the voltages profile during the restoration process, power generated by the generation units at each stage, the total load served increases with the stages, and power flows through the transmission lines and transformers at each stage.

\section{Proposed Methodology for Egyptian Utility Restoration}

Currently, the restoration in Egyptian NECC is performed step-by-step and mostly manually, based on pre-established guidelines and operating procedures. As power systems continue to grow in size and complexity, the amount of time required to restore power to customers in the aftermath of a blackout reaches a level which produces unacceptable economic and social costs for an industrialized society.

This section shows the description, formulation and results obtained from applying the proposed PSO technique to restore a sector of Egyptian Utility. 


\subsection{Problem Formulation}

The problem of restoration is formulated as an optimization problem; the objective function is to maximizing the served loads subjected to power balance and power flow constraints. Also control and state variables limits are considered.

Conditions of switching operation formulation of variables as controlled variables are considered as shown in Table].

Table 1 Conditions of Switching Operation (Control Variables)

\begin{tabular}{|c|c|c|}
\hline Variable & $\begin{array}{l}\text { Condition } \\
\text { (State) }\end{array}$ & Variable cype \\
\hline $\begin{array}{l}\text { Trensmission lines, } \\
\text { Irar sfommers and } \\
\text { generation units }\end{array}$ & On or oft & Binfry variables \\
\hline Loed restored & Yes or No & Binary variable \\
\hline Load percent & $\begin{array}{c}0 \%, 25 \%, 50 \% \\
75 \% \text { or } 100 \%\end{array}$ & Discrete variables \\
\hline $\begin{array}{l}\text { Voltages magnitude } \\
\text { at PV buses including } \\
\text { the slack bus }\end{array}$ & & $\begin{array}{l}\text { Conlinuous } \\
\text { variables }\end{array}$ \\
\hline $\begin{array}{l}\text { Real power at PV } \\
\text { buses excluding the } \\
\text { slack bus }\end{array}$ & & $\begin{array}{l}\text { Continuous } \\
\text { variables }\end{array}$ \\
\hline
\end{tabular}

The above variables determine the network configuration and the values of the control variables needed to perform a power flow analysis to the current system topology. The following variables are the state variables:

- Real and reactive power balance from power flow.

- Voltage magnitude at PQ buses.

- Power flow through transmission lines and transformers.

- Reactive power generation at PV buses including the slack bus.

- Real power generation at the slack bus.

\subsection{System Description}

The proposed methodology is applied to a sector of Egyptian Utility. The National Ene:gy Control Center has divided the Egyptian Utility into seven zones. The studied system represents the Middle Delta zone. This zone consists of fourteen buses; five of that fourteen are generation buses. The loads are connected to twelve buses.

Figures 3, 4 illustrate the studied zone where the generation plants (shown by Fig. 3) Domiata, Mahmoudia, Damanhur, Talkha, and Abu Soltan are connected to buses 1 to 5 respectively. There are 17 transmissions lines connected the buses and operate at $220 \mathrm{kV}$. Figure 3 shows the single line diagram of the studied zone, whereas the system detailed data are given in Appendix A. [21, 22].

\subsection{Control Variables}

The network parameters are modeled for PSO. These parameters are represented as control variables. There are fifty-five control variables for the studied sector. The first five positions of the control variables vector are the states of the five generation units. The next tweive control variables represent the states of the loads. The control variables that represent the transmission lines state are the next seventeenth variables. These thirty-four control variables are discrete binary variables and were handled using the PSO model as a binary variables.

The next twenty-one control variables are continuous variables and are handled using the PSO model for continuous variables. Each control variables vector or particle was evaluated according to the algorithm described in [23]. The control variables in the position from thirty-five, to thirty-nine are the voltage magnitudes of the generation units $\mathrm{G1}, \mathrm{G} 2, \mathrm{G} 3, \mathrm{G} 4$ and $\mathrm{G} 5$, respectively. These control variables are adjusted in the limit range specified $(0.9$ to $1.1 \mathrm{pu})$. The forty to forty-three control variables are the real power generation in MW of generation units G2, G3, G4 and G5, respectively. These control variables were adjusted in the limit ranges specified for each generation unit. The last twelve control variables vector are the load percent of each load. These variables were adjusted in the discrete range $(0 \%, 25 \%, 50 \%, 75 \%$ and $100 \%$ ) 


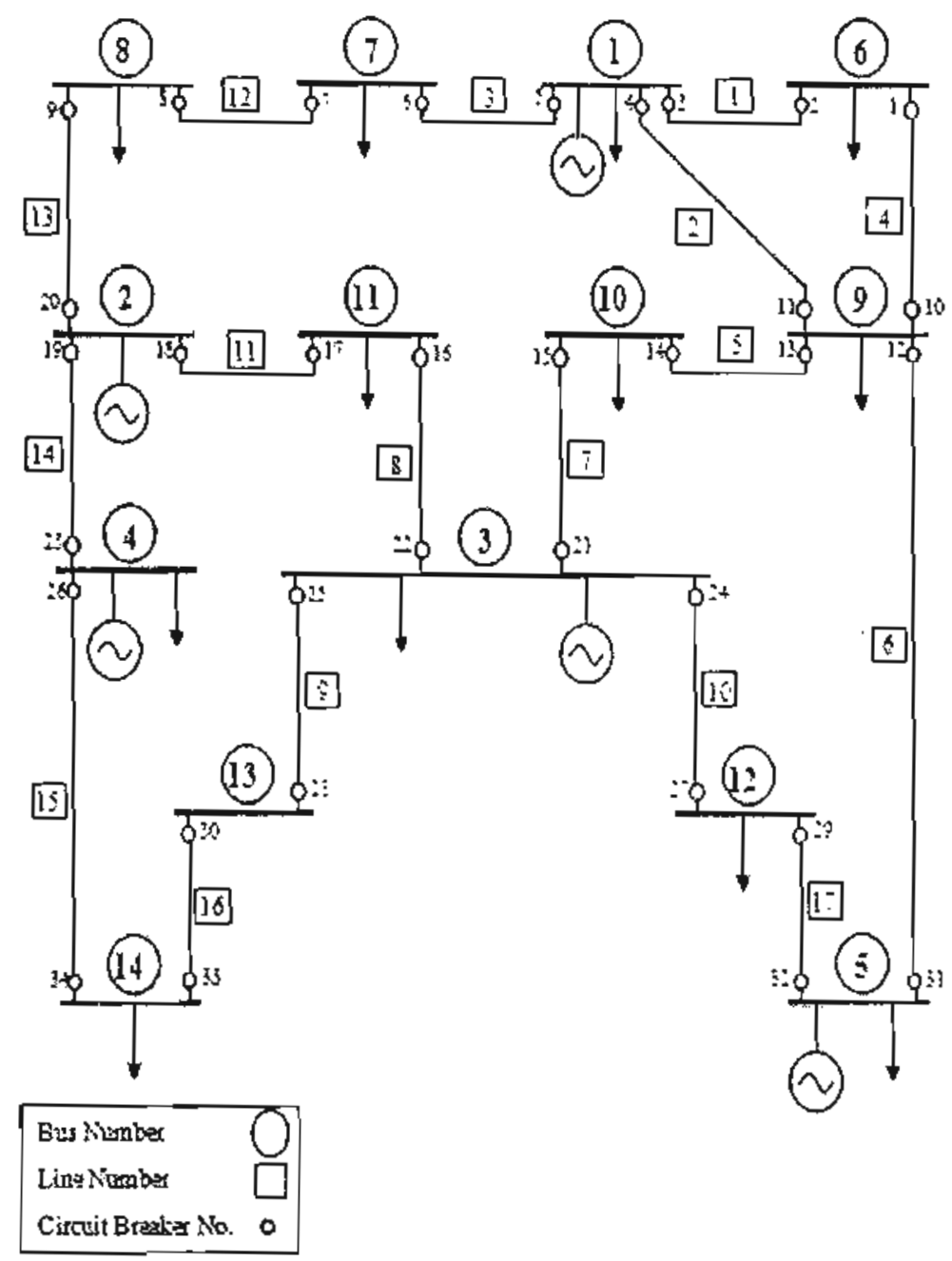

Figure 3 Single Line Dlagram of the Studied Sector

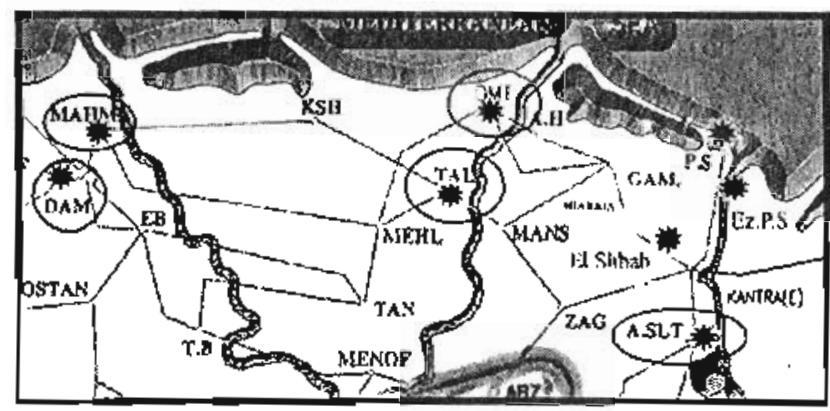

Flgure 4 Genteration Plants of the Studied Sector

\section{Results}

Based on the concept of multi-areas the system will be restored in multi-stages. The restoration process proposed was applied to a completely collapsed system. Therefore, all system devices were switched off. The following tables show the results obtained in each stage.

Table 2 shows the sequence of the restoration path. For each stage only one switching operation was performed. This table illustrates that the system is totally restored after 17 stages, and for every stage part of the network and the load would be restored. The sequence of restoring the whole system starts with connecting the generation unit $\mathrm{Gl}$ which is considered as the reference. In the second stage the load LI and L6 through transmission line L1-6 are restored and so on. Once the restoration 
process finished, all loads were served at $100 \%$. Also, all the generation units, transformers and transmission lines were switched on as shown in stage 17.

The voltage profiles during the restoration process are explained by Table 3 , no voltage was out of its limits. Table 4 shows the power generated by the generation units at each stage; no generation unit was out of its generation limits. According to the formulation, the main objective of the approach is to minimize the un-served loads. The total load served at each stage is shown in Table 5.

Finally, Table 6 shows the resultant power flow on each branch. The results are within the prescribed limits. The restoration path was established, all loads were served, and the restoration switching process was stated fulfilling all the problem constraints.

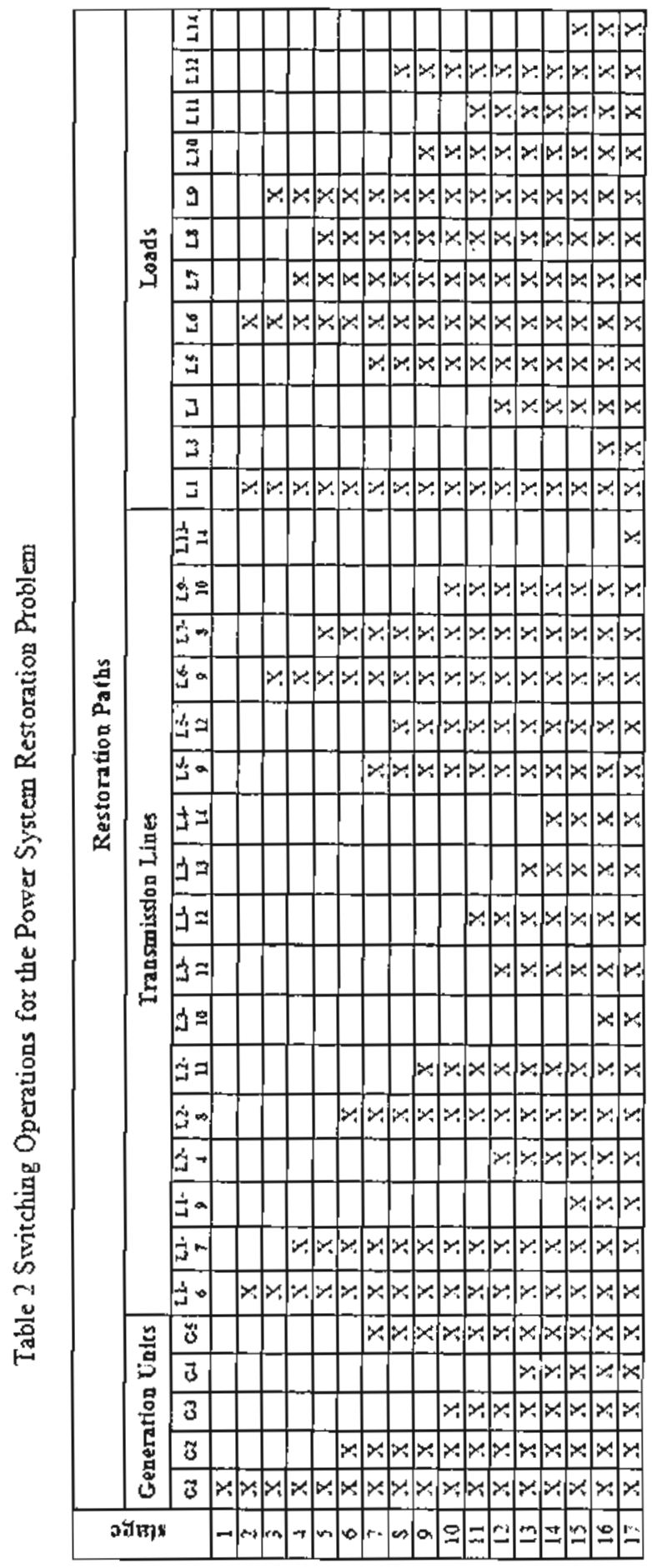


Mansoura Engineering Journal, (MEJ), Vol. 34, No. 2, June 2009.

E. 19

Table 3 Voltage Proflle during the Restoration Process

\begin{tabular}{|c|c|c|c|c|c|c|c|c|c|c|c|c|c|c|}
\hline \multirow{2}{*}{ stage } & \multicolumn{14}{|c|}{ Bus Volrage Magnitades (pa) } \\
\hline & $V I$ & $\sqrt{2} 2$ & $V 3$ & $\sqrt{4}$ & $1 / 5$ & $1 / 6$ & $V 7$ & 18 & 19 & VIO & $\nu l I$ & $V I 2$ & $v / 3$ & $V / 4$ \\
\hline 1 & 1.0 & & & & & 0.99 & & & & & & & & \\
\hline 2 & 1.0 & & & & & & 0.939 & & & & & & & \\
\hline 3 & 1.0 & & & & & & & & 0.984 & & & & & \\
\hline 4 & 1,0 & & & & & 0.984 & & & 0.968 & & & & & \\
\hline 5 & 1.0 & & & & & & 0.9003 & & 0.9582 & & & & & \\
\hline 6 & 1.0 & & & & 1.0 & & & & 0.942 & & & & & \\
\hline 7 & 1.0 & & & & & & & & 0.929 & 0.9842 & & & & \\
\hline 8 & 1.0 & 1.0 & & & & & 0.928 & 0.920 & & & & & & \\
\hline g & 1.0 & & & & 0.9 & & & & 0.958 & & & 0.97 & & \\
\hline 10 & 10 & & & & 1.0 & & & & 0.9502 & & & 0.9397 & & \\
\hline 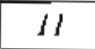 & 1.0 & & 0.9 & & & & & & 0.97 & 0.905 & & & & \\
\hline 12 & 1.0 & 0.9891 & & & & & 0.9826 & 0.9814 & & & 0.9891 & & & \\
\hline 13 & 1.0 & & & co & 1.0 & & & & 0983 & & & & & 0.943 \\
\hline 14 & 1.0 & & 1.0 & & 1.0 & & & & 09754 & & & 0.985 & & \\
\hline 15 & 1.0 & & 1.0 & & & & & & 0.98 & 0.979 & 0.938 & & & \\
\hline 16 & 1.0 & & 1.0 & & & & & & 0.989 & 0989 & & & 0.996 & \\
\hline 17 & 10 & & & 1.0 & 10 & & & & 0,977 & & & & 0.999 & 0.987 \\
\hline
\end{tabular}

Table 4 Active and Reactive Power Generated at each Stage

\begin{tabular}{|c|c|c|c|c|c|c|c|c|c|c|}
\hline \multirow{2}{*}{ stinge } & \multicolumn{10}{|c|}{ Generation Power $P(M W)$ and $Q(M V a r)$} \\
\hline & $P G I$ & $Q G l$ & $P G 2$ & $Q G 2$ & $P G 3$ & $Q G 3$ & $P G 4$ & $Q G A$ & $P G 5$ & $Q 65$ \\
\hline$I$ & 111.193 & 75.418 & & & & & & & & \\
\hline 2 & 110.239 & 82.083 & & & & & & & & \\
\hline 3 & 83220 & 54.617 & & & & & & & & \\
\hline 4 & 166.76 & 115.64 & & & & & & & & \\
\hline 5 & 402.44 & 268.29 & & & & & & & & \\
\hline 6 & $3 / 7.2$ & 203 & & & & & & & 600 & 182.79 \\
\hline 7 & 217.336 & 193.448 & & & & & & & & \\
\hline 8 & 175.99 & 138.9 & $3 / 7$ & 99.46 & & & & & & \\
\hline 9 & 104.9 & 112.9 & & & & & & & 600 & 1079 \\
\hline 10 & 417.09 & 271 & & & 1250 & 452 & & & & \\
\hline 11 & 775 & 568 & 317.4 & 284 & & & 495 & 280 & & \\
\hline 12 & 130 & 135 & $3 / 4$ & 219 & & & & & & \\
\hline 13 & 687 & 346 & & & & & 1250 & 145.5 & 600 & 146.6 \\
\hline 14 & $5 / 2.7$ & 147.7 & & & 1250 & 142.2 & & & & \\
\hline 15 & 360.4 & 379.1 & & & 1250 & $3 / 89$ & & & & \\
\hline 16 & 293.2 & 54.4 & 317.4 & $1 / 6.4$ & 495 & 288.13 & & & & \\
\hline 17 & 213369 & 112.076 & & & & & 1250 & 465.2 & 600 & 465.2 \\
\hline
\end{tabular}


Table 5 Total Load Served at each Stage

\begin{tabular}{|c|c|c|c|c|c|c|c|c|c|c|c|c|c|c|c|c|c|}
\hline stage: & 1 & 2 & 3 & 4 & 5 & 6 & 7 & 8 & 9 & 10 & 11 & 12 & 13 & 14 & 15 & 16 & 17 \\
\hline$P I$ & 28.0 & 28.0 & 28.0 & 280 & $11.8 / 3$ & 11813 & 28.0 & 13.813 & 11813 & 11813 & 28.0 & 11.813 & 11.813 & 118.813 & 71813 & $\pi / 8 / 3$ & $\sqrt{11813}$ \\
\hline$Q I$ & 17.0 & 17.0 & 17.0 & $J 7.0$ & 7.172 & 7.172 & 17.0 & 7.172 & 7.172 & 7.172 & 17,0 & 7.172 & 7.172 & 7.172 & 7172 & 7.172 & $7 \overline{172}$ \\
\hline$M I$ & $75 \%$ & $50 \%$ & $75 \%$ & $50 \%$ & $75 \%$ & $75 \%$ & $50 \%$ & $50 \%$ & $75 \%$ & $50 \%$ & $75 \%$ & $75 \%$ & $50 \%$ & $75 \%$ & $100 \%$ & $100 \%$ & $100 \%$ \\
\hline$P_{3}$ & & & & & & & & & & & 156 & & & 65.813 & 65813 & 65.813 & \\
\hline$\underline{Q}$ & & & & & & & & & & & 111. & & & 46.828 & 46628 & 46.878 & \\
\hline$M J$ & & & & & & & & & & & $75 \%$ & & & $75 \%$ & 1008 & $100 \%$ & \\
\hline$P 4$ & & & & & & & & & 43.031 & & & & 43.03 & & & & 430.037 \\
\hline 04 & & & & & & & & & 2.109 & & & & 2.109 & & & & 2.109 \\
\hline$M A$ & & & & & & & & & $75 \%$ & & & & $50 \%$ & & & & $100 \%$ \\
\hline$P 5$ & & & & & & 21051 & & & 210.51 & 91.125 & & & 210.5 & 21051 & & & 210,51 \\
\hline$Q 5$ & & & & & & 91.125 & & & $91 / 25$ & $\sin , 0$ & & & 91.12 & 91.125 & & & 91.125 \\
\hline$M S$ & & & & & & $75 \%$ & & & $75 \%$ & $50 \%$ & & & $50 \%$ & $75 \%$ & & & $100 \%$ \\
\hline P6 & 830 & & & 83,0 & & & & & & & & & & & & & \\
\hline 06 & 37.0 & & & 57.0 & & & & & & & & & & & & & \\
\hline Mt6 & & & & $50 \%$ & & & & & & & & & & & & & \\
\hline$P 7$ & & 81.0 & & & 34.172 & & & 34.172 & & & & 34.172 & & & & & \\
\hline$Q 7$ & & 56.0 & & & 23.625 & & & 23.025 & & & & 23.625 & & & & & \\
\hline$M 7$ & & & & & $75 \%$ & & & $50 \%$ & & & & $75 \%$ & & & & & \\
\hline$P B$ & & & & & 75.094 & & & 75.094 & & & & 75,094 & & & & & \\
\hline$Q 8$ & & & & & 58.641 & & & 58.641 & & & & $58.64 !$ & & & & & \\
\hline$M s$ & & & & & $75 \%$ & & & $50 \%$ & & & & $75 \%$ & & & & & \\
\hline$P 9$ & & & 55.0 & 55.0 & & 23.203 & 55.0 & & 23.203 & 32.203 & 550 & & 23.20 & 23.203 & 23.2013 & 23.203 & 23.203 \\
\hline$Q^{9}$ & & & 36.0 & 360 & & 15.188 & 360 & & 75.188 & 15188 & 36.0 & & 1518 & $15.18 \overline{8}$ & 15.188 & 15.188 & $15.7 \overline{88}$ \\
\hline$M 9$ & & & & & & $75 \%$ & $50 \%$ & & $75 \%$ & $50 \%$ & $75 \%$ & & $\overline{50 \%}$ & $75 \%$ & $100 \%$ & $100 \%$ & $100 \%$ \\
\hline$P 10$ & & & & & & & 128. & & & & 128. & & & & 54.0 & 54.0 & \\
\hline Q10 & & & & & & & 940 & & & & 940 & & & & 39.656 & 39.656 & \\
\hline M10 & & & & & & & $50 \%$ & & & & $75 \%$ & & & & $100 \%$ & $100 \%$ & \\
\hline$P \|$ & & & & & & & & & & & & 50.625 & & & 50.625 & & \\
\hline$Q M$ & & & & & & & & & & & & $34 \overline{594}$ & & & 34.594 & & \\
\hline$M I I$ & & & & & & & & & & & & $75 \%$ & & & $100 \%$ & & \\
\hline$P / 2$ & & & & & & & & & & .143 .43 & & & & $14,3.43$ & & & \\
\hline$Q / 2$ & & & & & & & & & & 13.078 & & & & 13,078 & & & \\
\hline$M / 2$ & & & & & & & & & & $.50 \%$ & & & & $75 \%$ & & & \\
\hline PIA & & & & & & & & & & & & & 49.35 & & & & 49.359 \\
\hline 214 & & & & & & & & & & & & & 36.70 & & & & 36.703 \\
\hline$M$ & & & & & & & & & & & & & $50 \%$ & & & & $100 \%$ \\
\hline
\end{tabular}

Table 6 Resultant Power Flow on each Branch

\begin{tabular}{|c|c|c|c|c|c|c|c|c|c|c|c|c|c|c|c|c|c|}
\hline sfage & 1 & 2 & 3 & 4 & 5 & 6 & 7 & 8 & 9 & 10 & 11 & 12 & 13 & 14 & 15 & 16 & 17 \\
\hline$L I .6$ & 93.971 & & & 160.85 & & & & & & & & & & & & & \\
\hline$L I, 7$ & & 66 & & & & & 26896 & 81.744 & & & & 134.05 & & & & & \\
\hline$L 1.9$ & & & 99.105 & & 77.970 & & & & 316.56 & & 45.078 & & 264.96 & 282.01 & 105.11 & 120.16 & 248.41 \\
\hline$L 2.4$ & & & & & & 145,06 & & & & & & & & & & & \\
\hline$L 28$ & & & & & & & & 148.78 & & 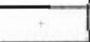 & & 85,204 & & & & & \\
\hline$L 2\rfloor$. & & & & & & & & & & & $\sqrt{3.483}$ & & & & & & \\
\hline$L 3.10$ & & & & & & & & & & 265.83 & & & & & $7 \overline{86.62}$ & 201.57 & \\
\hline$L 3, I I$ & & & & & & & & & & & & & & 35.440 & 82.003 & & \\
\hline$L 3.13$ & & & & & & & & & & & & & & & & 76,925 & 59.500 \\
\hline$L A . I A$ & & & & & & & & & & & & 50.365 & & & & & \\
\hline$L 5.9$ & & & & 47.841 & & & & & 22673 & & & & 218.43 & 140.84 & & & 183.54 \\
\hline$L 5 . / 2$ & & & & & & & & & 102.50 & & 7 & & 69.009 & 78725 & & & 132.32 \\
\hline 26.9 & & & & 26606 & 95,008 & & & & & & & & & & & & \\
\hline$L>8$ & & & & & & & 225.77 & & & & & 58.821 & & & & & \\
\hline 29.10 & & & & & & & & & & & 354.11 & & & & 105.92 & 72099 & \\
\hline$L I 2.3$ & & & & & & & & & & & & & 18570 & & & & 101.99 \\
\hline$L 13.14$ & & & & & & & & & & & 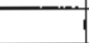 & 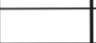 & & & & & 34.808 \\
\hline
\end{tabular}




\section{Conclusion}

Restoring a power system after a partial or complete collapse in a minimal amount of time presents a very complex problem.

This paper presents an evolutionary approach-based methodology to solve power system restoration problem. The proposed methodology can be used to solve the restoration problem of large electric systems with multiple generation units and transmission loops.

The methodology is applied to restore a sector of Egyptian Utility after a complete blackout. Currently, the restoration in Egyptian NECC is performed step-by-step and mostly manually, based on preestablished guidelines and operating procedures.

Results show effectiveness and validity of the proposed EA-based methodology compared to pure human experience in Egyptian NECC. The technique can help decision makers in the Egyptian NECC of how to restore the network after full or partially black out events.

In the future work authors intended to apply that technique in a real time for large utilities.

\section{References}

[1] J. A. Huang, L. Audette and S. Harrison, "A Systemalic Method for Power System Resioration Planning", IEEE Trans. on Power Systems, Vol. 10, No. 2, May 1995.

[2] M. El-Hawary, "Introduction to Electrical Power Systems" book, John Wiley \& Sons, inc., Publication, 2008, pp. 371379

[3] D. Kirschen, T. Volkmann "Guiding a Power Restoration with An Expert System", IEEE Transaction on power system, Vol.6, No.2, May 1991.

[4] C.C. Liu "Optimizing Power System Resioration Resources and Actions" Department of Electrical and Computer Engineering Iowa State University Research Tele-seminar Nov. 7, 2006.
[5] T. Nagata and H. Sasaki, "A Mulli-Agent Approach to Power System Restoration", IEEE Trans. on Power Systems, Vol. 17, No. 2, May 2002.

[6] M. M. Adibi, et.al, "Expert System Requirement for Power System Restoration", IEEE Trans, on Power Systems, Vol.9, No.3, August 1994.

[7] D. Kirschen, T. Volkmann "Guiding a Power Restoration wilh An Experl System", IEEE Transaction on power system, Vol.6, No.2,May 1991.

[8] P. Gomes, A. Carlos S. d. Lima," Guidelines for Power System Restoration in the Brazilian System", IEEE Transactions on Power Systems, Vol. 19, No. 2, May 2004.

[9] T. Nagata, H. Sasaki and R. Yokoyama, "Power System Restoration by Joint Usage of Expert System and Mathematical Programming Approach", IEEE Transactions on Power Systems, August 2004.

[10] J. A. Huang, F. D. Galiana and G. $\Upsilon$. Vuong, "Power System Restoration Incorporating Interactive Graphics and Optimization", IEEE Power Industry Computer Application Conference 1991 , Conference Proc. 7-10, pp. 216222.

[11] T. Kobayashi, et.al., "Verification of an Advanced Power System Restoration Support System Using Operator Training Simulator", IEEE Trans. on Power Systems, Vol.9, No.2, May 1994.

[12] Ch. Brook, V. Ranganathan, and N. N. Sebulz." A Case Study on Blackout Restoration as an Educcional Tool", IEEE Trans. on Power Systems, Vol. 15, No. 2, May 2000.

[13] A. S. Btetas and A. Phadke "Power System Restoration using Artificial Neural Nerworks", $33^{\text {rd }}$ Annual North American Power Symposium, 2001, College Station, Texas.

[14] J. C. Mendes, O. R. Saavedra and J. O. Pessanha, "Power System Restoration with Priority Loads Using an Evolutionary Strategy Approach", 34th 
North America Power Symposium, Tempe, Arizona State University.

[15] A.S. Bretas, et.al, "Artificial Neural Networks in Power System Restoration", IEEE Transaction on Power Systems, Vol.18, No.4, October 2003.

[15] T. S. Chan and M. K. Tiwari, "Swarm Intelligence Focus on Ant and Particle Swarm Optimization", book, Tech Education and Publishing, Vienna, Austria, 2007

[17] A. Carlos et al.; "Evolutionary Algorithms for Solving Multi-Objective Problems" book, Springer publisher, 2007

[13] L.C. Jain et al.; "Introduction to Evolutionary Computing in System Design", Studies in Computational Intelligence (SCI) 66, 2007, pp.1-9.

[19] E. Zitzler, and L. Thiele, "Multiobjective evolutionary algorithms: a comparative case study and the strength Pareto approach", IEEE Transactions on Evolutionary Computation, Volume 3, Issue 4, Nov. 1999, pp. $257-271$

[20] R. Eberhart, and J. Kennedy, "A New Optimizer using Particle Swarm Theory", Proceedings the Six ${ }^{\text {th }}$ International. Symposium, Micro Machine Human Science, Vol. 4-6 October, 1995 , pp. 39-43.

[21] M. S. Kandil, K. M. Sheble, K. Yassin and M. F. Kotb, "Power System Restoration Methodology with Particular Reverence to Island Detection", The sixth international Middle East Power Systems Conference MEPCON'98, Mansoura, Egypt.

[22] M. M. El-Saadawi, A. E. Hassan, and R. R. Ebrahim "Framework of Particle Swarm Intelligence Optimization for Power System Resloration" , Al-Azhar Engineering $10^{\text {th }}$ International Conf. AEIC2008, Cairo 24-26 Dec. 2008.

[23] "2007-2008 Annual Report of Egyptian Electricity Holding Company EEHC", Ministry of Electricity \& Energy, available at: http://www.moee.gov.eg/
8. Appendix

\section{Studied $220 \mathrm{kV}$ Sector Data [21]}

Table A-l Generation linits Dato

\begin{tabular}{|l|l|l|l|l|}
\hline \multicolumn{1}{|c|}{ Bus } & $\begin{array}{l}\text { Min. } \\
\text { MW }\end{array}$ & $\begin{array}{l}\text { Max. } \\
\text { MW }\end{array}$ & $\begin{array}{c}\text { Min. } \\
\text { MVAR }\end{array}$ & $\begin{array}{c}\text { Max. } \\
\text { MVAR }\end{array}$ \\
\hline Demyat & 0 & 1200 & 0 & 800 \\
\hline Mahmodyea & 0 & 317.4 & 0 & 211 \\
\hline Talkha & 0 & 1250 & 0 & 830 \\
\hline Damanhour & 0 & 495 & 0 & 330 \\
\hline Abositan & 0 & 600 & 0 & 350 \\
\hline
\end{tabular}

Table A-2 Bus Dafa

\begin{tabular}{|l|l|l|l|l|}
\hline Bus & \multicolumn{1}{|c|}{ Type } & $\begin{array}{c}\text { Voltage } \\
\mathrm{kV}\end{array}$ & $\begin{array}{c}\text { Load } \\
\mathrm{MW}\end{array}$ & $\begin{array}{c}\text { Load } \\
\text { MVAR }\end{array}$ \\
\hline 1 & $\mathrm{PV}$ & 220 & 280 & 117 \\
\hline 2 & $\mathrm{PV}$ & 220 & 0 & 0 \\
\hline 3 & $\mathrm{PV}$ & 220 & 156 & 111 \\
\hline 4 & $\mathrm{PV}$ & 220 & 102 & 5 \\
\hline 5 & $\mathrm{PV}$ & 220 & 499 & 216 \\
\hline 6 & $\mathrm{PQ}$ & 220 & 183 & 57 \\
\hline 7 & $\mathrm{PQ}$ & 220 & 81 & 56 \\
\hline 8 & $\mathrm{PQ}$ & 220 & 178 & 139 \\
\hline 9 & $\mathrm{PQ}$ & 220 & 55 & 36 \\
\hline 10 & $\mathrm{PQ}$ & 220 & 128 & 94 \\
\hline 11 & $\mathrm{PQ}$ & 220 & 120 & 82 \\
\hline 12 & $\mathrm{PQ}$ & 220 & 340 & 31 \\
\hline 13 & $\mathrm{PQ}$ & 220 & 0 & 0 \\
\hline 14 & $\mathrm{PQ}$ & 220 & 117 & 87 \\
\hline
\end{tabular}

Table A-3 Branch Dara

\begin{tabular}{|l|l|l|l|l|l|}
\hline From & To & $\begin{array}{c}\mathrm{R} \\
\mathrm{P} . \mathrm{U}\end{array}$ & $\begin{array}{c}\mathrm{X} \\
\mathrm{p.u}\end{array}$ & $\begin{array}{c}\mathrm{B} / 2 \\
\text { p.u }\end{array}$ & $\begin{array}{l}\text { Rating } \\
\text { MVA }\end{array}$ \\
\hline $\mathrm{I}$ & 6 & .00187 & .01372 & .0845 & 220 \\
\hline 1 & 9 & .004944 & .03624 & .2232 & 176 \\
\hline 1 & 7 & .011266 & .08258 & .5088 & 176 \\
\hline 6 & 9 & .004944 & .03524 & .2232 & 176 \\
\hline 9 & 10 & .008509 & .06237 & .38417 & 176 \\
\hline 9 & 5 & .018727 & .13727 & .8454 & 220 \\
\hline 10 & 3 & .002546 & .01866 & .11498 & 176 \\
\hline 3 & 11 & .0135 & .049418 & .2225 & 132 \\
\hline 3 & 13 & .021375 & .01083 & .3523 & 132 \\
\hline 3 & 12 & .024375 & .1235 & .5495 & 220 \\
\hline 11 & 2 & .00618 & .0627 & .279 & 132 \\
\hline 7 & 8 & .0042136 & .03088 & .19027 & 165 \\
\hline 8 & 2 & .01053 & .0772 & .4755 & 165 \\
\hline 5 & 4 & .005175 & .01894 & .0853 & 132 \\
\hline 4 & 14 & .00945 & .04788 & .15578 & 132 \\
\hline 14 & 13 & .01035 & .05244 & .1706 & 132 \\
\hline 12 & 5 & .028425 & .1425 & .4636 & 220 \\
\hline
\end{tabular}

